\title{
Effects of Annealing on Structure and Magnetic Properties of Fe-Si-Al Flakes
}

\author{
Pyungwoo Jang* \\ College of Science and Engineering, Cheongju University, Cheongju 28503, Republic of Korea
}

\begin{abstract}
This study elucidates the effects of annealing on the properties of Fe-Si-Al flakes. The changes of the $\mathrm{DO}_{3}$ phase, the lattice parameter and the grain size of the flakes were analyzed by X-ray peak broadening and shift. Static magnetic properties, namely, coericivity and saturation magnetization, were analyzed by a vibration sample magnetometer (VSM). The complex permeability spectra were measured by a precision impedance analyzer. The cocercivity and the real part of the complex permeability had the lowest and highest values after $1023 \mathrm{~K}$ annealing. The change in the magnetic properties with annealing temperature is successfully explained by relief of residual stress and the formation of $\mathrm{DO}_{3}$ and $\mathrm{B} 2$ ordered phases.
\end{abstract}

(Received July 5, 2018; Accepted July 25, 2018)

Keywords: $\mathrm{Fe}-\mathrm{Si}-\mathrm{Al}$ flake, $\mathrm{DO}_{3}$ hase, residual stress, complex permeability

\section{INTRODUCTION}

Near field communication (NFC) is a promising wireless technology that is now widely used in transportation cards, food control, electronic payment systems, etc. However, perturbations in electromagnetic waves; i.e., changes in the magnetic field, can easily affect the NFC system. One of the main sources for perturbation in a magnetic field is a metal plate because a metal plate with high electrical conductivity emits electromagnetic fields by eddy currents induced in the metal plate after it receives a communication signal from an antenna. Insertion of a magnetic sheet with high permeability and low eddy current loss between the antenna and the metal plate can solve this problem. In order to manufacture the magnetic sheets, soft magnetic powder or flakes are mixed with polymer resin and then the mixture is casted by doctor blade method [1,2].

An NFC system typically uses a several megahertz frequency, so the electrical resistivity of the flake should be high. Zero magnetostriction can be obtained in a Fe-Si binary system using $6.5 \mathrm{wt} \% \mathrm{Si}$. However, this composition apparently cannot be applied to the flakes for the sheet because the resistivity is too low. Instead $\mathrm{Fe}-9 \% \mathrm{Si}-2 \% \mathrm{Cr}$ alloy flakes with higher electrical resistance have been used

*Corresponding Author: Pyungwoo Jang [Tel: +82-43-229-8553, E-mail: pwjang@cju.ac.kr] Copyright (c) The Korean Institute of Metals and Materials
[2]. The Fe-9.5\%Si-5.5\%Al alloy, normally known as sendust, has soft magnetic properties superior to the Fe$9.5 \% \mathrm{Si}-2 \% \mathrm{Cr}$ alloy because the $\mathrm{Fe}-\mathrm{Si}-\mathrm{Al}$ alloy simultaneously shows zero crystalline anisotropy, zero magnetostriction and high electrical resistivity. For the NFC application the spherical Fe-Si-Al particles are deformed into flakes under controlled conditions in an attrition mill to obtain higher permeability even though it is very brittle. The as-milled FeSi-Al flakes do not have good soft magnetic properties because of residual strain induced during the milling. Therefore, the micro-structure of the as-milled flakes need to be controlled by a process such as annealing to impart high electrical resistivity and low coercivity, thereby leading to high permeability [3-6].

The ordered $\mathrm{B} 2(\mathrm{FeSi})$ and $\mathrm{DO}_{3}\left(\mathrm{Fe}_{3} \mathrm{Si}\right)$ phases are known to form when the silicon content is higher than 5.4\% $\mathrm{Si}$ [7]. $\mathrm{B} 2(\mathrm{FeAl})$ and $\mathrm{DO}_{3}\left(\mathrm{Fe}_{3} \mathrm{Al}\right)$ phases also form in the Fe-Al system. There have been some controversies over the terminology of the $\mathrm{FeSi}$ ordered phase because the $\mathrm{FeSi}$ ordered phase forms only with a specific stoichiometric composition. Some researchers believe that the structure of the $\mathrm{FeSi}$ ordered phase is not $\mathrm{B} 2$ but $\mathrm{B} 20$ [8]. Moreover, others use $\alpha_{2}$ to emphasize that the B2 phase is an incomplete $\mathrm{DO}_{3}$ phase as well as to highlight that the phase has a bodycentered cubic crystal system [9]. Instead of $\alpha_{1}$ and $\alpha_{2}, B 2$ and $\mathrm{DO}_{3}$ were used in this study because those are widely used terms. 
For an NFC application, magnetic properties of the magnetic sheet have been measured. However, the magnetic properties of the sheets do not stand for the properties of the flakes embedded in them. Instead of the magnetic sheets, others also made a composite membrane [10]. It is well known that the packing fraction, particle alignment, dispersion and others influence magnetic properties of the magnetic composites [11]. In our previous results on Fe-Si$\mathrm{Cr}$ sheets, it was very difficult to get identical properties even though the process variables, such as mixing ratio, casting variables and others, were fixed [2]. To avoid these difficulties, instead, the permeability spectra of the flakes were directly measured for which the flakes were packed in a capsule without any medium in a precision impedance analyzer. We also investigated the effects of annealing on the structure and magnetic properties of the $\mathrm{Fe}-9.5 \% \mathrm{Si}-5.5 \% \mathrm{Al}$ flakes with a focus on the order-disorder transition.

\section{EXPERIMENTAL PROCEDURE}

Gas-atomized $\mathrm{Fe}-9.5 \% \mathrm{Si}-5.5 \% \mathrm{Al}$ powder was milled in an attrition mill in a controlled environment. Subsequently the as-milled flakes were sieved to have an average length of 80 $\mu \mathrm{m}$. The sieved flakes were annealed at $298-1323 \mathrm{~K}$ for 1 hour in a hydrogen atmosphere and then furnace-cooled, for which the quartz tube was evacuated and then filled with the $99.999 \%$ hydrogen prior to the annealing.

The crystal structure, grain size, lattice parameter and degree of ordering were analyzed by X-ray diffractometer, XRD (Rigaku, SmartLab, $9 \mathrm{~kW}$ ), using $\mathrm{Cu}_{K_{\alpha_{1}}}$ radiation. To measure the grain size and the $\mathrm{DO}_{3}$ phase of the flakes, instrumental broadening was corrected by the equation $\beta=\left(B_{\text {sample }}^{2}-B_{r e f}^{2}\right)^{1 / 2}$ where $B_{\text {sample }}$ and $B_{r e f}$ are the full width at half maximum (FWHM) of the sample and the reference, respectively. The reference pure iron powder (Alfa Aesar, 200 mesh) was annealed in a pure hydrogen atmosphere at $1073 \mathrm{~K}$ for 24 hours. Peaks diffracted from $\mathrm{Cu}_{K_{\alpha_{1}}}$ radiation were deconvoluted by an XPS fitting program (Version 4.1). True lattice parameters of the Fe-Si-Al flakes were determined by the procedure of Cullity and Stock [12]. The lattice parameter was calculated for each peak and plotted against the corresponding value of $\cos ^{2} \theta / \sin \theta$, where $\theta$ is the Bragg angle. Linear fit was done and the intercept of the $y$-axis obtained by the extrapolation, which was taken as a true lattice parameter of the flake. The degree of long range ordering $(D L R O)$ was measured by the equation $D L R O=$ $\left[\left(I^{s} / I^{f}\right) /\left(I_{o}^{s} / I_{o}^{f}\right)\right]^{1 / 2}$, where $I^{s}$ and $I^{f}$ are the integral intensities of the superlattice and fundamental peak, respectively, after annealing and $I_{o}^{s}$ and $I_{o}^{f}$ are the integral intensities of the same lines in the fully ordered sample [13]. The morphology of the annealed flakes was observed by scanning electron microscope (SEM).

Static magnetic properties were measured by a home-made VSM under a maximum field of $620 \mathrm{kA} / \mathrm{m}$. For VSM analysis, a small amount of the Fe-Si-Al flakes with a nearly equal mass of $0.071 \mathrm{~g}$ was weighed to exclude change in the demagnetization field with the changing mass and then compacted into a small capsule. Complex permeability was measured up to $140 \mathrm{MHz}$ by an Agilent 4294A precision impedance analyzer and a test fixture for $16454 \mathrm{~A}$ magnetic materials, for which the annealed flakes were filled in a toroid-capsule with an inner diameter of $10 \mathrm{~mm}$, an outer diameter of $15.5 \mathrm{~mm}$ and a height of $4.6 \mathrm{~mm}$. The masses of the flakes were $0.2290-0.2292 \mathrm{~g}$.

\section{RESULTS AND DISCUSSION}

Figure 1 shows SEM images of the as-milled and the annealed Fe-Si-Al flakes. The shape of the flakes is irregular

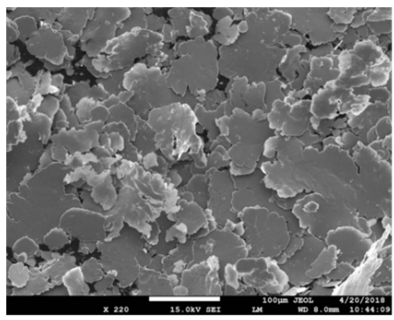

(a)

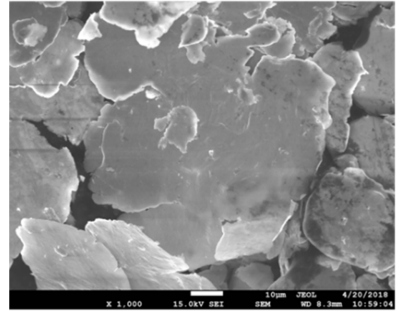

(c)

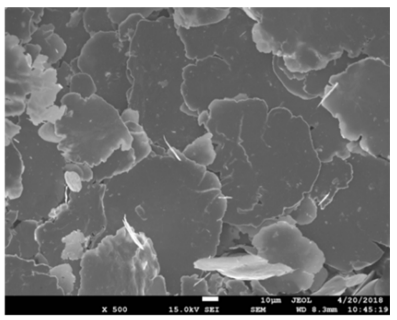

(b)

(d)

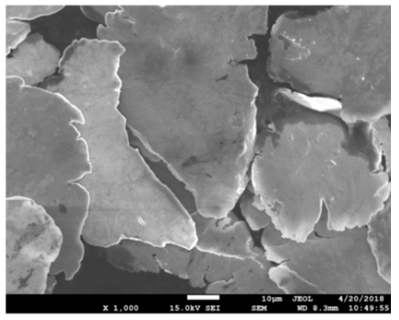

Fig. 1. SEM images of the as-milled and the annealed Fe-Si-Al flakes. (a) as-milled flakes (x220), (b) as-milled flakes (x1000), (c) flakes annealed at $1023 \mathrm{~K}$, (d) flakes annealed at $1323 \mathrm{~K}$ (x1000). 


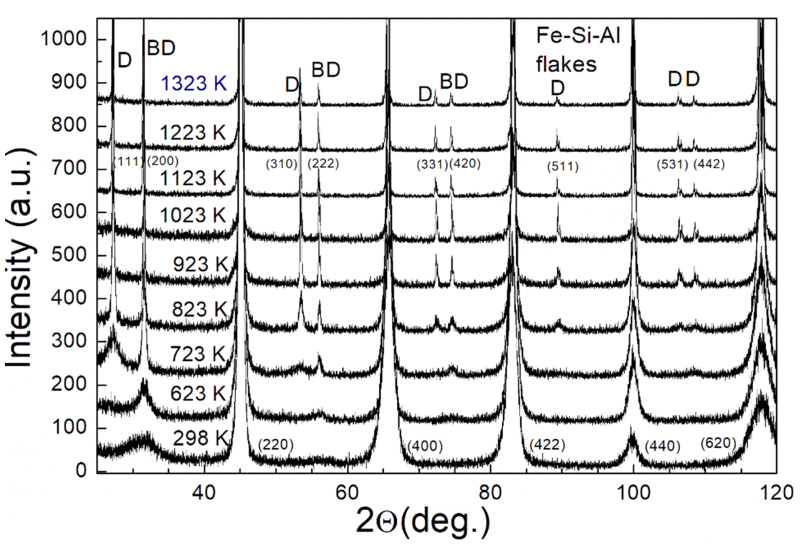

Fig. 2. Variation of XRD patterns of the Fe-Si-Al flakes annealed at $298-1232 \mathrm{~K}$.

and the thickness of the flakes is around $1 \mu \mathrm{m}$. The images show a wide size distribution ranging from several micrometers to around a hundred micrometers so that the average aspect ratio is around several tens. The images of the annealed flakes do not change after annealing even though the flakes partly conglomerate after annealing at $1323 \mathrm{~K}$.

Figure 2 shows the XRD patterns of the annealed flakes where the indices refer to those of the $\mathrm{DO}_{3}$ phase and marks $\mathrm{D}$ and $\mathrm{B}$ denote the $\mathrm{DO}_{3}$ and $\mathrm{B} 2$ phases, respectively. The (111) peak is a representative characteristic peak of the $\mathrm{DO}_{3}$ phase, whereas the (200) peak is diffracted from both the B2 and $\mathrm{DO}_{3}$ phases. The (111) peak does not appear in the asmilled flake, whereas the (200) peak is present at around $2 \theta$ $=31.5^{\circ}$. The intensity ratio of the (111) peak to the (200) peak, $I_{(111)} / I_{(200)}$, of the fully ordered and randomly oriented Fe-Si-Al flakes is about 1.7 as shown later. Thus, this means that the formation of the $\mathrm{B} 2$ phase was not suppressed during the gas-atomization process and the as-milled flakes also contain the $\mathrm{B} 2$ phase. This is due to the fact that the $\mathrm{B} 2$ phase is not stable at room temperature but stable at a temperature higher than $1073 \mathrm{~K}$ as shown in the $\mathrm{Fe}-9.5 \% \mathrm{Si}-5.5 \% \mathrm{Al}$ ternary phase diagram $[14,15]$. In our previous study on gasatomized $\mathrm{Fe}-7-9 \% \mathrm{Si}-2 \% \mathrm{Cr}$, the formation of $\mathrm{B} 2$ phase was not suppressed during the atomization process and milling process $[2,16]$. The peaks in the as-milled flakes were very broad, which means the grains were very small. When the flakes were annealed at $723 \mathrm{~K}$, the $\mathrm{DO}_{3}$ phase was detected. With a further increase in the annealing temperature, all the peaks became sharper and stronger.

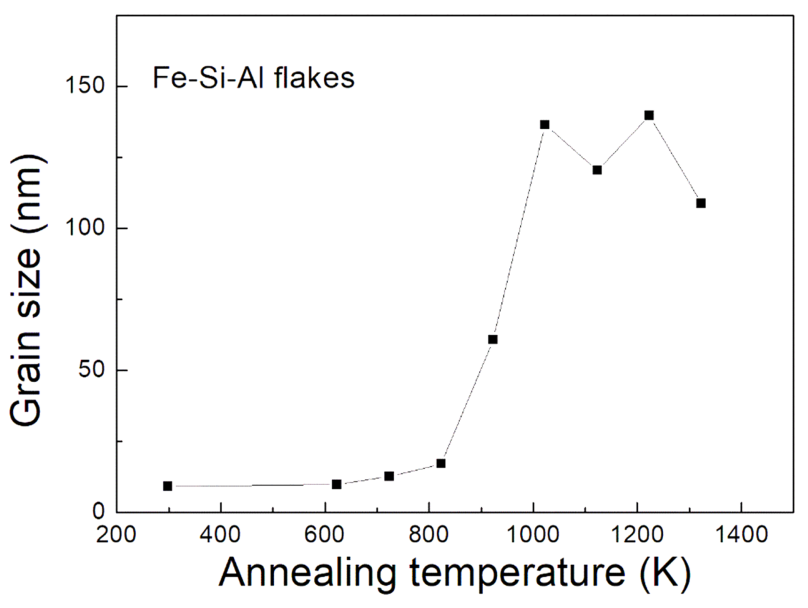

Fig. 3. Variation of grain size of the Fe-Si-Al flakes annealed at $298-1232 \mathrm{~K}$.

Fig. 3 shows the variation in the average grain size of the flakes with the annealing temperature. The grain size was obtained by Scherrer's equation even though it can be reasonably applicable in a range of 0-200 $\mathrm{nm}$. The calculated grain size of the as-milled flakes were about $9.3 \mathrm{~nm}$. After $923 \mathrm{~K}$ annealing, the grain size increased rapidly. The Williamson-Hall equation has been widely used to measure grain size and strain simultaneously. However, this equation is known to be inapplicable when the degree of anisotropic deformation is severe as in this study [17]. To solve this problem modified the Williamson-Hall equation was also proposed $[17,18]$. In this study both equations were tested to measure the grain size and the strain of the flakes, but scattering of data was so severe so that the fitted values were meaningless. The grain size decreased after $1123 \mathrm{~K}$ annealing, which seems to be due to the formation of the B2 phase, which is stable above $1073 \mathrm{~K}$.

Figure 4 shows the variation of the true lattice parameter of the Fe-Si-Al flakes with the annealing temperature. Peaks diffracted by $\mathrm{Cu}_{K_{\alpha_{1}}}$ radiation $(\lambda=0.15406 \mathrm{~nm})$ in the flakes annealed below $923 \mathrm{~K}$ could not be deconvoluted because the peaks were too broad, as shown in Fig. 2. In this case, an averaged $\mathrm{Cu}_{K_{\alpha}}$ wavelength of $0.15418 \mathrm{~nm}$ was used. All the plots of the lattice parameter versus the $\cos ^{2} \theta / \sin \theta$ showed straight lines except 298, 623, and $723 \mathrm{~K}$ flakes. The deviation from straight line in these flakes seems to be due to distortion of the body centered cubic (bcc) cell, which seems to be due to both anisotropic deformation and incomplete 


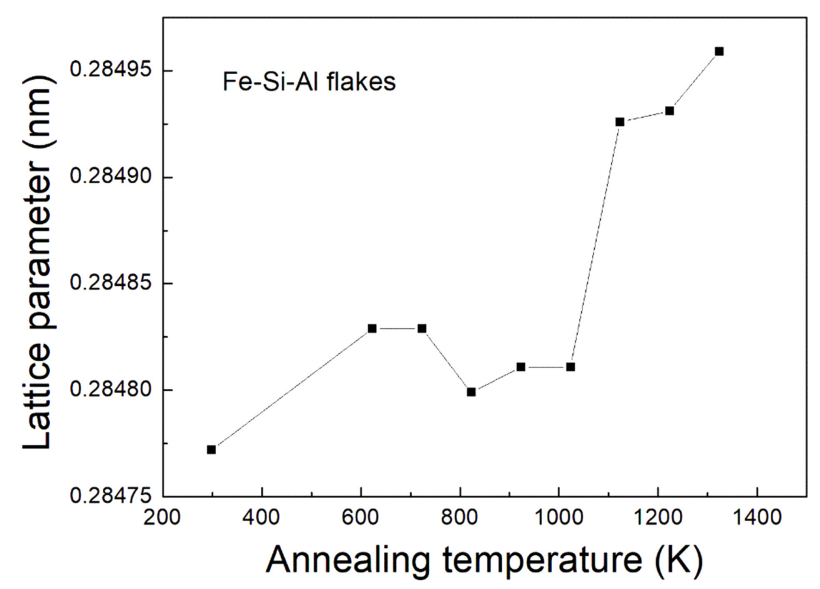

Fig. 4. Variation of lattice parameter of the Fe-Si-Al flakes annealed at $298-1232 \mathrm{~K}$.

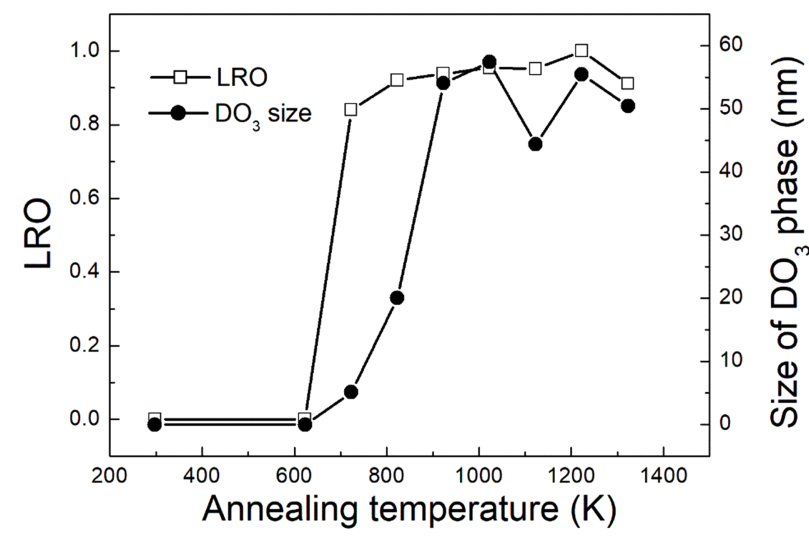

Fig. 5. Variation of $L R O$ and $\mathrm{DO}_{3}$ size of the Fe-Si-Al flakes annealed at $298-1232 \mathrm{~K}$.

relief of residual stress. The lattice parameter increased with the annealing temperature and there was a rapid increase after $1123 \mathrm{~K}$ annealing. This rapid increase seems to be related to reappearance of $\mathrm{B} 2$ phase.

Figure 5 shows the variation in the $D L R O$ and $\mathrm{DO}_{3}$ size of the flakes with the annealing temperature. For the calculation of the DLRO the (111) and (220) peaks were used as superlattice and fundamental lines, respectively. When the temperature increased up to $627 \mathrm{~K}, L R O$ did not occur. The $D L R O$ increased very rapidly after $723 \mathrm{~K}$ annealing, reached the maximum at $1023 \mathrm{~K}$ and then decreased slightly. According to the Fe-Si-Al ternary phase diagram, the B2 phase is stable above $1073 \mathrm{~K}[14,15]$. When the Fe-Si-Al flakes were annealed above $1073 \mathrm{~K}$, the $\mathrm{DO}_{3}$ phase formed in the heat-up stage or early stage of the annealing because

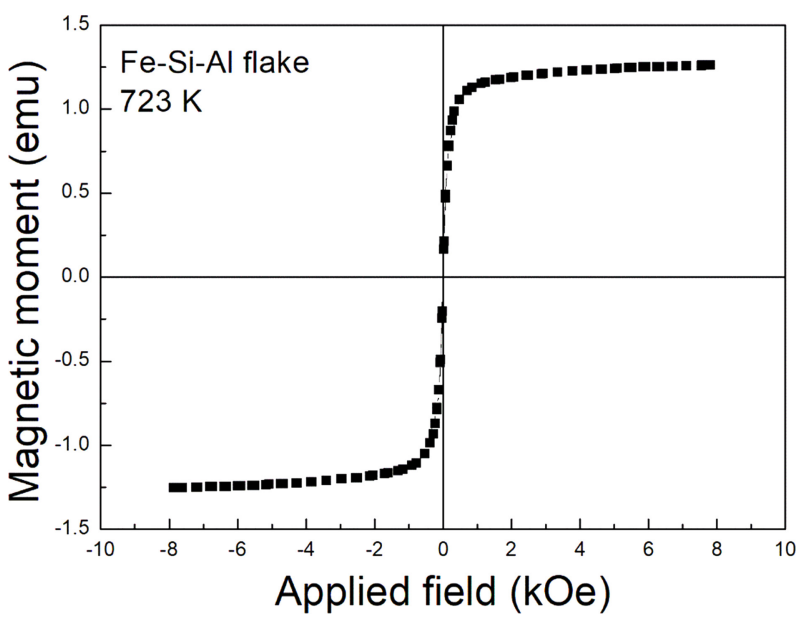

Fig. 6. VSM loop of the Fe-Si-Al flakes annealed at $723 \mathrm{~K}$.

the $\mathrm{DO}_{3}$ phase was stable at a lower temperature. In the latter stage of the annealing, the $\mathrm{B} 2$ phase formed by the reaction of $\mathrm{DO}_{3} \rightarrow \mathrm{A} 2+\mathrm{B} 2$. The $\mathrm{B} 2$ phase formed in this way remained at room temperature because the cooling rate was not so low in this experiment (rate $\fallingdotseq 20 \mathrm{~K} / \mathrm{min}$ from $1123 \mathrm{~K}$ to $873 \mathrm{~K}$ ). While the $D L R O$ increased very rapidly after 723 $\mathrm{K}$ annealing, the $\mathrm{DO}_{3}$ phase grew rapidly after a higher annealing temperature of $923 \mathrm{~K}$. Although the $L R O$ had a relatively high value of 0.84 after annealing at $723 \mathrm{~K}$, the size of the $\mathrm{DO}_{3}$ phase was as small as $5.1 \mathrm{~nm}$. Comparing Fig. 5 with the temperature dependence of the grain size in Fig. 3 the growth of the $\mathrm{DO}_{3}$ phase occurred at a temperature 200 $\mathrm{K}$ lower than that of the grain growth. Decrease in the size of the $\mathrm{DO}_{3}$ phase at $1123 \mathrm{~K}$ seems to be due to the transformation of the $\mathrm{DO}_{3}$ phase to the $\mathrm{B} 2$ phase.

Figure 6 shows the VSM loop of the $723 \mathrm{~K}$ flakes. Under a maximum field of $620 \mathrm{kA} / \mathrm{m}$ the magnetization of the flake was nearly saturated. For the VSM measurement, the flakes were compacted into a cylindrical capsule to have the shape of a disc, the aspect ratio of which was as high as 50. This high aspect ratio saturated the flakes under the maximum field with reduced demagnetization of the compact. The saturation magnetization of the $1232 \mathrm{~K}$ flakes was around $122 \mathrm{Am}^{2} / \mathrm{kg}$ which was nearly same as the others $[3-4,6$,$] .$

Figure 7 shows variations in the coercivity and saturation magnetization of the flakes with the annealing temperature. With an increasing temperature, the coercivity starts to drop rapidly at a relatively low temperature of $723 \mathrm{~K}$, decreases 


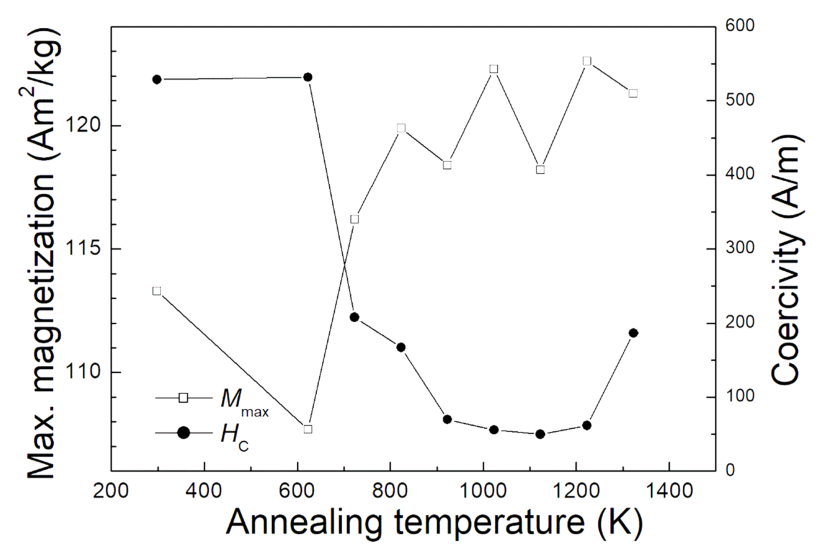

Fig. 7. Variations of coercivity and saturation magnetization of the $\mathrm{Fe}-\mathrm{Si}$-Al flakes with annealing temperature.

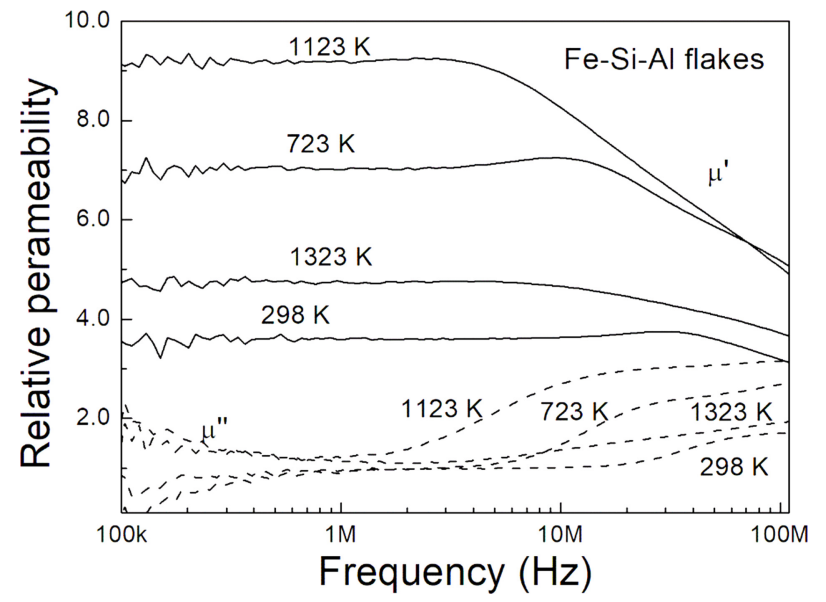

Fig. 8. Variation of frequency dependencies of the permeability of the $\mathrm{Fe}-\mathrm{Si}$-Al flakes with annealing temperature.

gradually above the temperature, shows a lowest coercivity of $49.8 \mathrm{~A} / \mathrm{m}$ at $1123 \mathrm{~K}$ and then increases. The decrease in the coercivity is due to both relief of the residual stress and grain growth. The rapid decrease in the coercivity above 723 $\mathrm{K}$ is mainly due to the stress relief, which can be inferred from Fig. 5 in which the $D L R O$ increases rapidly above 723 $\mathrm{K}$. The gradual decrease above $1023 \mathrm{~K}$ is due to both additional stress relief and grain growth. The increase in the coercivity in the $1323 \mathrm{~K}$ flakes seems to be due to a conglomeration of the flakes after annealing. The saturation magnetization increased with the annealing temperature. The increase in the saturation magnetization is due to the evolution of the $\mathrm{DO}_{3}$ phase [3].

Figure 8 shows the variation in the spectra of the permeability of the flakes annealed at 298, 723, 1123 and

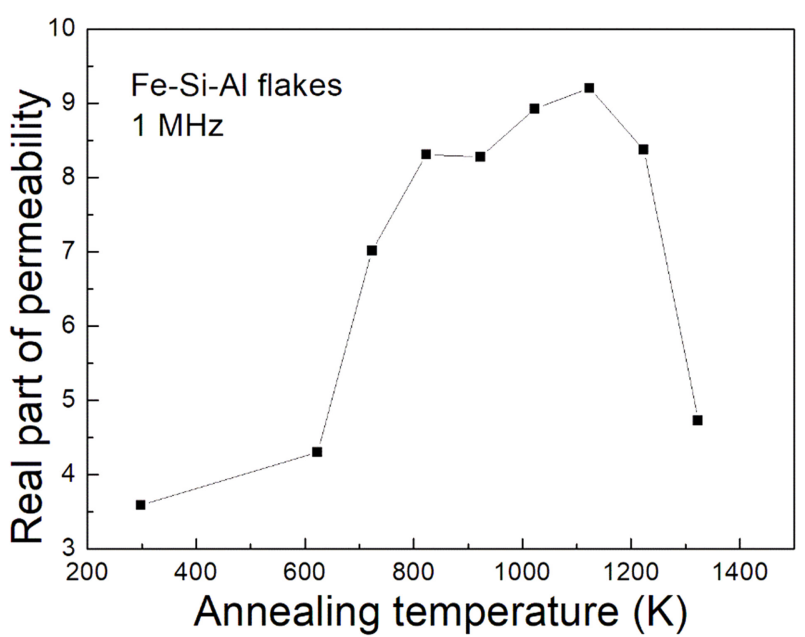

Fig. 9. Variation of the real part of the permeability with the annealing temperature.

$1323 \mathrm{~K}$. The higher the real part of the permeability becomes, the higher the imaginary part becomes. The real part of permeability persists up to a higher frequency in the flakes with reduced permeability. Figure 9 shows the variation in the real part of the permeability of the flakes with the annealing temperature. With an increasing temperature, the real part increased and then decreases rapidly above $1223 \mathrm{~K}$. A highest value of 9.2 was obtained after $1123 \mathrm{~K}$ annealing. The real part decreased to 4.7 after $1323 \mathrm{~K}$ annealing, which seemed to be caused by the agglomeration of the flake and the reappearance of the B2 phase. Thus, the optimum annealing temperature range for the as-milled flakes in this study were $1023-1123 \mathrm{~K}$. The increase in the permeability was certainly due to the relief of residual stress, which reduced the coercivity of the flakes. The annealing temperature for the lowest coercivity coincided with that of the highest real part of the permeability. This is different from others where they measured magnetic properties of the Fe-Si$\mathrm{Al}$ sheets and the temperature for minimum coercivity was much higher than that for maximum complex permeability [6].

\section{CONCLUSION}

In this study, the as-milled flakes contained both the disordered A2 phase and the $\mathrm{B} 2$ phase, while the $\mathrm{DO}_{3}$ phase was not detected in the XRD experiment. With an increasing annealing temperature, the $\mathrm{DO}_{3}$ phase and the grain grew 
rapidly. However, the starting ordering temperature for the $\mathrm{DO}_{3}$ phase or $L R O$ was $200 \mathrm{~K}$ lower than that of the grain growth. The cocercivity and the real part of the complex permeability had lowest and highest values after $1023 \mathrm{~K}$ annealing. The above results confirms that stress relief plays an important role.

\section{REFERENCES}

1. S. J. Lee, Y. B. Kim, K. S. Lee, and S. W. Kim, J. Magn. 12, 49 (2007).

2. P. W. Jang, S. J. Moon, D. W. Han and K. S. Lee, J. Mag. Mag. Mater. 377, 436 ( 2015).

3. J. S. Shin, J. S. Bae, H. J. Kim, H. M. Lee, T. D. Lee, E. J. Lavernia, and Z. H. Lee, Mater. Sci. Eng. A 407, 282 (2005).

4. A. I. Al-Sharif, M. Abu-Jafar, and A. Qteish,, J. Phys.: Condens. Matter. 13, 2807 (2001).

5. K. Hilfrich, W. Kölker, W. Petry, O. Schärpf, and E. Nembach, Scripta Metall. Mater. 24, 39 (1990.)

6. M. Abshinova, Procedia Eng. 76, 35(2014).

7. L. Liu, Z. H. Yang, C. R. Deng, Z. W. Li, M. A. Abshinova, and L.B.Kong, J. Mag. Mag. Mater. 324, 1786( 2012).

8. B. D. Cullity, Introduction to Magnetic Materials, pp.385389, Addison-Weseley Publishing company, Massachusetts
(1972).

9. B. D. Cullity and S. R. Stock, Elements of X-ray Diffraction, $3^{\text {rd }}$ edition, pp.375-381, Pearson Education Limited, Edinburgh Gate, England (2014).

10. A. Guinier, X-ray Diffraction in Crystals, Imperfect Crystals and Amorphous Bodies, pp.259, W. H. Freeman and Co., San Francisco and London (1963).

11. M. C. J. Marker, B. Skolyszewska-Kuhberger, H. S. Effenberger, C. Schmetterer and K. W. Richer, Intermetallics 19, 1919 (2011).

12. Y. Du, J. C. Schuster, Z. Liu, R. Hu, P. Nash, W. Sun, W. Zhang, J. Wang, L. Zhang, C. Tang, Z. Zhu, S. Liu, Y. Ouyang, W. Zhang, and N. Krendelsberger, Intermetallics 16, 554 (2008).

13. P. W. Jang and G. H. Choi, IEEE Trans. Magn. 53, 2002705 (2017).

14. T. Ungar and G. Tichy, Phys. Stat. Sol. A 171, 425 (1999).

15. T. Ungar, I. Dragomir, A. Revesz, and A. Borbely, J. Appl. Crystallogr. 32, 992 (1999).

16. T. Ma, M. Yan, and W. Wan, Scripta Mater. 58, 243 (2008).

17. Q. Li, Z. Feng, S. Yan, Y. Nie, and X. Wang, J. Elect. Mater. 44, 3777 (2015).

18. Y. Shimada, K. Suzuki, K. Nomura, and K. Fukamichi, J. Appl. Phys. 93, 6659 (2003). 